\title{
EGR and Injection Timing Variation Effects of an Engine Run in HCCI Mode Performance and Emitted Emissions
}

\author{
Miqdam T Chaichan ${ }^{\# 1}$, Khalil I Abaas ${ }^{* 2}$ \\ Mechanical Engineering Department, UOT, Baghdad, Iraq
}

\begin{abstract}
Homogeneous charge compression ignition (HCCI) combustion can extend the operation of diesel engine to achieve better performance. HCCI can reduce NOx emissions by the low combustion temperatures resulted from the introduction of a fraction of EGR. Also, it can reduce PM by utilizing the premixed charge combustion.

Direct injection multi-cylinder water cooled diesel engine used in this study. The tests procedure consisted of the addition of EGR starting from $0 \%$ till burning misfire occurred. Two cases were examined: first case, the injection of diesel fuel at advanced injection timing 35 degrees before top dead center $\left({ }^{\circ}\right.$ BTDC). At the second case; the diesel fuel injected at retarded injecting timing of $12^{\circ}$ BTDC. All these cases compared with operating the diesel engine with neat diesel and no EGR addition.

The tests results illustrated that retarding injection timing led to a high increase in bsfc by about $17 \%$. Also, it reduced brake thermal efficiency by about $20.88 \%$. While operating the engine with advanced injection timing and 50\% EGR resulted in reverse outcomes. Also, tested emissions HC, NOx, PM and engine noise were reduced remarkably compared with operating the engine with neat diesel and no EGR.
\end{abstract}

Keywords - HCCI, NOx-PM trade-off, CO, HC, noise.

\section{INTRODUCTION}

The demand for diesel engines increased in the recent years highly. This increment correlated with diesel engine good fuel economics. Also, the increasing output power due to using a turbocharger in these engines that operates with high compression ratios accompanied by advanced technologies to reduce noise. Many techniques have been developed to reduce emitted exhaust gas emissions from these engines in the last years. PM traps that can reduce this pollutant to near zero concentration are an example of these techniques. Also, NOx catalyst is used for several years to eliminate this pollutant [1].

Direct injection diesel engine sells increased depending on it's fuel economy. Also, it took advantage of the development of high-pressure injection systems that reduce emitted emissions and improve fuel consumption. High-pressure injection can reduce the emitted PM by enhancing fuel droplets and it's mixing with the air. The diesel fuel combustion can be more improved by using homogeneous compression ignition (HCCI) combustion mode. This combustion method has two valuable advantages: reducing NOx concentrations due to low combustion temperatures resulted from the existence of the recirculated exhaust gas. Also, it reduces PM concentrations owing to the usage of the premixed charge in this system [2 \& 3].

Diesel fuel combustion starts with fuel injection in pressurized air where the combustion timing controlled entirely. In HCCI engine, the homogeneous charge consists of a mixture of compressed air and fuel combustion starts when the suitable conditions attained. So, the ignition starting that control the combustion has no particular definition in this operation mode. If the engine designed in techniques that make the combustion conditions monitored, at one operation point. Then, changing the output work of the engine will be impractical. The controlling system must change the combustion causing reasons as compression ratio, gas temperature and pressure inside combustion chamber to achieve dynamic operation in HCCI engine [4]. HCCI engine operates in lean mixtures, and the maximum resulted temperature is lower compared with traditional diesel engine. This low maximum temperature prevents the formation of NOx, but it produces incomplete combustion especially near combustion chamber wall. This condition increases $\mathrm{CO}$ and HC concentrations [5 \& 6]. The primary difficulty with HCCI engine represents in controlling an engine run with a wide range of speeds and loads. The ignition determination of HCCI engine comes from charge components and the relation between time and temperature, with a lower extent charge pressure. Many methods suggested for controlling HCCI system combustion as EGR variation, using variable compression ratios (VCR), using variable valves timing (VVT). These methods were used to vary compression ratio and or the EGR inside the combustion chamber. VCR and VVT techniques are practically attractive due to fast response for acceleration and deceleration conditions [7, 8 \& 9].

Fuel injection considered as one of the main methods of controlling the HCCI mode combustion. The operation with this technique must be studied deeply because the combustion processes depend on fuel injection, ignition timing and injected fuel quantity. Also, the total injected fuel with respect to engine load. Diesel engine with its injection system proper operation demands the balance between all these factors to be achieved [10].

Several advantages can be gained from fuel injection near top dead center compared to fuel injection in entering manifold [1]. Fuel injection near top dead center of the compression stroke means the combustion chamber temperature reached a limit that facilitates fuel vaporization and improves its mixing with the air. This procedure allows cooler air to enter the combustion chamber and reduces the early fuel ignition tendency. The main disadvantage of late direct injection is the lack of time needed to mix the air with fuel. A high NOx and PM concentrations may appear as in airfuel partially mixing. This condition cause combustion chamber is wetting with fuel [7]. 
EGR is one of the new diesel engines characteristics; it plays an essential role in reducing NOx emissions. Many researchers mentioned that NOx concentrations reduced with rates ranged between 30 to $75 \%$ with EGR addition in 5 and $25 \%$ [11 \& 12]. Also, fuel consumption affected in a small manner with EGR usage compared with using injection timing retardation that affect directly NOx concentrations. EGR utilization reduces the maximum combustion temperature that affects directly NOx. There are three factors explain this EGR effects on NOx concentrations: increases the delay period, increases the thermal capacity and diluting the entering charge with inert gasses [13]. As EGR increases delay period then, it has the same effect of injection timing retardation. Increasing thermal capacity means that the gasses need more heat to reach a particular temperature. EGR addition, as a result, produces lower burning temperatures. Adding inert gasses reduce adiabatic flame temperature. EGR addition has disadvantages also. It increases engine wear. It increases PM and $\mathrm{HC}$ concentrations. The need for additional components to install in the engine intake system is an extra cost [14].

$\mathrm{PM}$ and $\mathrm{HC}$ concentrations increase at high engine load operation due to adding EGR that reduces oxygen concentration. The increment in engine wear is due to the friction between PM existed in the suction air in addition to the sulphuric acid accompanied with EGR that spoil lubrication oil [15].

The dependence of NOx concentrations emitted from a diesel engine on emitted PM concentrations one of the most disadvantages of diesel engines. The proceeded processes from the moment of fuel are leaving the injector holes until the fuel ignition are very complicated. Processes like droplets formation, the collation of them, its crash and its evaporation and vapor distribution and other processes taking place during this period [16]. The air fuel ratio inside combustion chamber whether it was lean, rich or stoichiometric, has an influence. Rich mixture causes smoke while lean and stoichiometric mixtures produce high flame temperatures causing higher NOx concentrations. PM oxidation depends mainly on temperature, so practically the tendency for PM reduction increases NOx concentrations. This problem called "diesel dilemma" that is the fundamental challenge of achieving the future emissions limitations imposed by USA and Europe governments for these two pollutants [17 \& 18].

Mathematical simulation reliance or single cylinder engines operation used by many published papers to get rid of the several variables accompanied with multi-cylinder operation. So, in this paper the aim was to operate a direct injection diesel engine with HCCI mode. The study investigates the effect of cooled EGR addition with variable volumetric ratios (20 and $50 \%$ ) on the engine operation. Two controlling procedures used: first, advanced injection timing during the second retarded injection timing. Engine characteristics and emitted emissions compared with their comparables resulted from engine operated with Iraqi diesel fuel. The aim was to clarify the effect of running the engine in HCCI mode at low burning temperatures and lean equivalence ratios.

\section{EXPERIMENTAL SETUP}

Direct injection multi-cylinder water cooled FIAT diesel engine used in this study. Table 1 gives the basic engine specifications. The engine is connected to a hydraulic dynamometer to measure the subjected load. This dynamometer calibrated using several calibrated weights. Exhaust gas analyzer type (Multigas model 4880) was used to measure $\mathrm{NOx}, \mathrm{CO}_{2}, \mathrm{CO}$, and $\mathrm{HC}$ concentrations. This device calibrated at the central organization for measurements and specific control-Baghdad, and the calibrations results listed in Table 3. Total sound pressure rate measured by sound pressure level meter supplied by amplifier type 4615 . This meter calibrated for standard calibration meter type (pisto phone 4220), and calibration results list in Table 3.

The air collecting device with low volume type (Sniffer L30) was used to collect the engine emitted particulate matters. Glass micro-filters types (Whatmann) were used for this process. These filters weighed before and after finishing from collecting the sample that extended to one hour. The equation determined PM concentrations [6]:

$$
P M \operatorname{in}\left(\frac{\mu g}{m^{3}}\right)=\frac{w_{2}-w_{1}}{V_{t}} \times 10^{6}
$$

Vt found by the equation:

$$
V t=Q_{t} \cdot t
$$

Each used filter was preserved in a plastic container temporarily until finishing from collecting all samples and weighing and analyzing the results.

\section{EGR System}

EGR system type Prodit used in this study appeared in fig.1. The exhaust gas recirculated through two openings. One opening at exhaust manifold and the second at suction manifold. The EGR cooled by means of two pipes heat exchanger. The hot exhaust gas pass through the inner tube (one with a lower diameter) and cooling water through the outer tube (one with a larger diameter) that surround the exhaust gas pipe. The required heat exchanging takes place. Exhaust gas temperature controlled by means of the flowing water rate while the EGR quantity was entering the suction manifold controlled by means of EGR valve. The EGR quantity is measured by orifice and mercury manometer. Tow primary points considered in this system:

First, the system must be able to recirculate a quantity from exhaust gas its percentage attained more than $50 \%$. This procedure was necessary to ensure reaching flame quenching point due to high EGR levels. The second, the EGR pipe must be as short as possible to prevent exhaust gasses cooling more than the required degrees. Extra EGR cooling may cause longer delayed ignition due to low temperatures for lean HCCI mixtures. Also, it may cause lean quenching limits. 


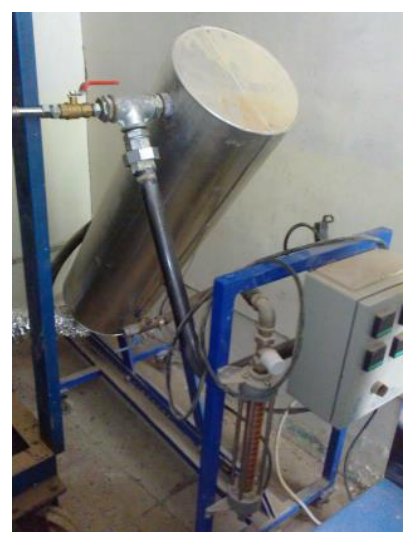

Fig. 1 EGR system in this study type Prodit

\section{The Used Fuel}

Iraqi diesel fuel was used in the recent investigation as a reference fuel. It was produced and analyzed at Al-Doura Refinery in Baghdad. Iraqi diesel fuel characterized by its moderate cetane number (49.5 in this study) and its high sulfur content (1\% in this study). Table 2 lists a summarized description of Iraqi diesel fuel; all the analyzing tests conducted at Al-Doura refinery/ Baghdad-Iraq laboratories.

Tests Procedure

The action of operating an engine in HCCI mode divided into three headings. First, premixed HCCI system, where fuel is injected into the air in the suction manifold before it enters the combustion chamber. Second, HCCI system using advanced injection timing. In this system, the fuel is injected into the cylinder with advanced injection timing before TDC that allows mixing the air and fuel before the self-ignition point. The last is direct retarded injection timing HCCI system. In this system, the fuel injection timing is delayed from the standard injection timing of the traditional engine. Also, a turbulent circulation and high mixing with high rates of EGR used to delay ignition period. This procedure enables the sufficient mixing of fuel and the air before self-ignition. In the recent study, the possibilities of using the two last systems, were investigated.

The engine speed fixed at $1500 \mathrm{rpm}$ using neat diesel fuel with engine standard injection timing $21^{\circ} \mathrm{BTDC}$. The engine left to run until its cooling water reached $90^{\circ} \mathrm{C}$. Cooled EGR quantity entering the suction manifold was changed starting from $0 \%$ until the engine was shut down due to reaching the quenching limit. Flame quenched due to lack of oxygen needed for combustion. The engine subjected load changed, and the tests repeated for each load. The engine performances measurements accompanied by the measurements of emissions and emitted noise obtained for each case. The tests repeated for advanced injection timing $35^{\circ}$ BTDC. The required measurements recorded for engine performance, emissions, and noise. This procedure preferred by about $50 \%$ of the researchers in controlling HCCI system combustion. In the last set of experiments retarded injection timing $\left(12^{\circ} \mathrm{BTDC}\right)$ was used accompanied with cooled EGR with the same rates used in the former tests and the required measurements were taken. The study focused on the engine performance and emissions at two injection timings $12^{\circ} \mathrm{BTDC}$ and $35^{\circ} \mathrm{BTDC}$ for a wide range of engine loads. The results compared with those resulted from operating the engine with a neat Iraqi diesel with standard injection timing without EGR. Noise level measured in all cases by fixing the overall sound pressure meter $110 \mathrm{~cm}$ from the engine center in all directions. The following equations used in calculating the engine performance [19]:

Brake power (bp):

$$
b p=\frac{2 \pi * N * T}{60 * 1000}
$$

Brake mean effective pressure (bmep):

Fuel mass flow rate:

$$
b m e p=b p \times \frac{2 * 60}{V_{s n} * N}
$$

$$
\dot{m}_{f}=\frac{v_{f} \times 10^{-6}}{1000} \times \frac{\rho_{f}}{\text { time }}
$$

Actual air mass flow rate

$$
\dot{m}_{a, \text { act. }}=\frac{12 \sqrt{h_{o} * 0.85}}{3600} \times \rho_{\text {air }}
$$

Theoretical air mass flow rate

$$
\dot{m}_{a_{\text {theo. }}}=V_{s . n} \times \frac{N}{60 * 2} \times \rho_{\text {air }}
$$

Brake specific fuel consumption (bsfc):

$$
b s f c=\frac{\dot{m}_{f}}{b p} \times 3600
$$

Fuel's total heating value

$$
Q_{t}=\dot{m}_{f} \times L C V
$$

Brake thermal efficiency $\left(\eta_{t h}\right)$ :

$$
\eta_{\text {bth. }}=\frac{b p}{Q_{t}} \times 100 \quad \%
$$

EGR quantity was measured by the equation [9]:

$$
\operatorname{EGR}(\%)=\frac{m_{E G R}}{\dot{m}_{E G R}+\dot{m}_{a}} \times 100
$$

\section{Error Analysis}

Errors source and uncertainty for the recent study were defined and determined for the used measuring devices. This analysis was conducted to ensure the reliance on tests results. Table 3 lists the measuring devices and its accuracy used in the recent investigation. Uncertainty defined as the knowledge of error worth by knowing the differences between the 
measured and real quantities. The uncertainty in each single measurement leads to uncertainty in all the experiment. In general, the test uncertainty can be expressed by the equation [20]:

$$
e_{R}=\left[\left(\frac{\partial R}{\partial V_{1}} e_{1}\right)^{2}+\left(\frac{\partial R}{\partial V_{2}} e_{2}\right)^{2}+. .+\left(\frac{\partial R}{\partial V_{n}} e_{n}\right)^{2}\right]^{0.5}
$$

Where:

$\mathrm{e}_{\mathrm{R}}$ : results uncertainty.

$\mathrm{R}$ : given function consists of independent variables $\left(\mathrm{V}_{1}\right.$, $\left.\mathrm{V}_{2}, \ldots, \mathrm{V}_{\mathrm{n}}\right)$ or $\mathrm{R}=\mathrm{R}\left(\mathrm{V}_{1}, \mathrm{~V}_{2}, \ldots, \mathrm{V}_{\mathrm{n}}\right)$.

$\mathrm{e}_{\mathrm{i}}$ : uncertainty range for the variables

The partial differential $\frac{\partial R}{\partial V_{1}}$ represents the sensitivity of one variable.

So, the uncertainty for the recent study was:

$$
\begin{aligned}
e_{R}=\left[(.36)^{2}+\right. & (.96)^{2}+(.82)^{2}+(.88)^{2}+(.74)^{2} \\
& +(1.4)^{2}+(.67)^{2}+(.22)^{2}+(.68)^{2} \\
& \left.+(.8)^{2}\right]^{0.5}=\mp 2.57 \%
\end{aligned}
$$

To ensure repeatability all the tests were repeated for three times and the results average was taken as a consequence.

\section{Results and Discussion}

Fig. 2 shows the effect of cooled EGR addition to the suction air on brake specific fuel consumption at constant load and speed. The engine run at specific standard injection timing $21^{\circ} \mathrm{BTDC}$, results in the minimum bsfc compared to running with advanced injection timing $35^{\circ} \mathrm{BTDC}$ or retarded injection timing $12^{\circ}$ BTDC. Precise increment found with IT retardation case with about $16.17 \%$ compared to standard IT. Engine operation with advanced IT means the engine can achieve the required time for fuel and the air to mix entirely. While the retarded IT means, there is no available time for mixing and a part of the fuel burned in the power stroke after the piston dropped down. The curves clarify that operating the engine with a retarded IT caused engine shutdown at EGR rates near $70 \%$. However, in the other cases the engine stopped at EGR rate near $80 \%$. High EGR rates supplied to the combustion chamber at the expense of the suction air that cause engine shutdown due to lack of the air.

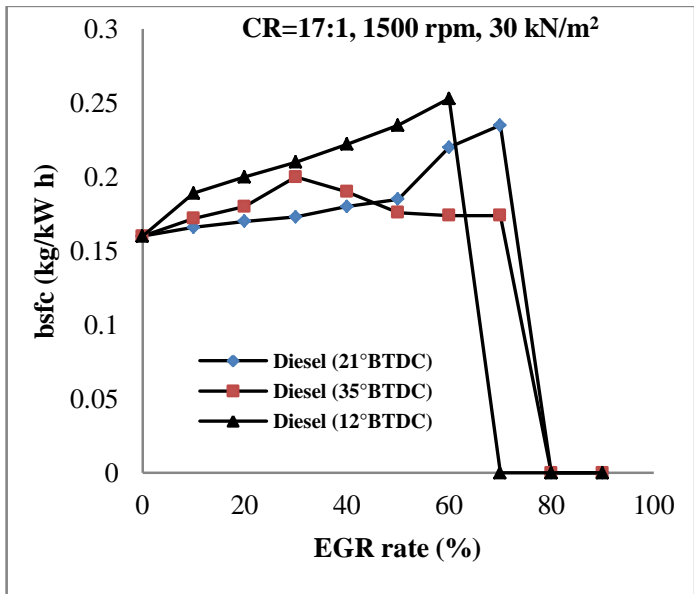

Fig.2 The effect of EGR rate on bsfc
Fig. 3 represents the effect of load on the bsfc for operating the system in HCCI mode and comparing it with traditional diesel engine operation. Diesel engine consumed the lower bsfc at medium pressures from 23 to $60 \mathrm{kN} / \mathrm{m}^{2}$ and operated for high loads. For $35^{\circ}$ BTDC and $20 \%$ EGR, the loads range is limited till $60 \mathrm{kN} / \mathrm{m}^{2}$. Also, the lower consumption range became restricted between 38 and $44 \mathrm{kN} / \mathrm{m}^{2}$. With $50 \%$ EGR addition rate, at the same IT the engine behavior varied from the former case apparently.

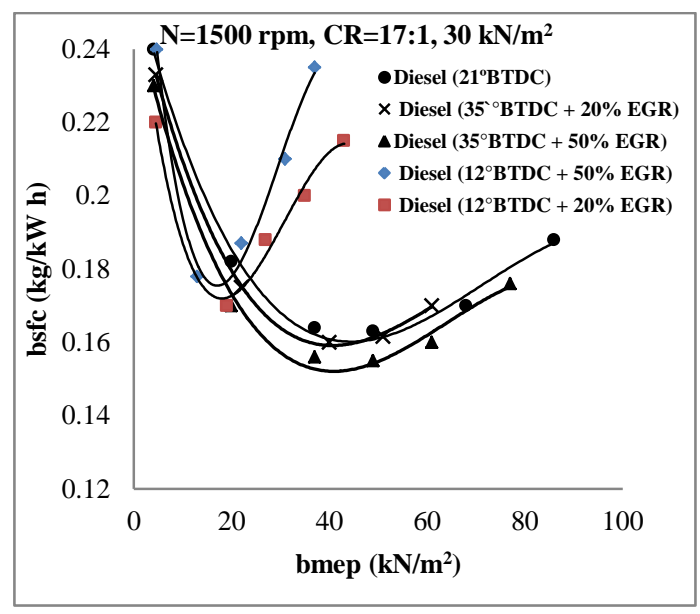

Fig.3 Engine load variation effect on bsfc for studied cases

The operation load range extended to $80 \mathrm{kN} / \mathrm{m}^{2}$, and the lower bsfc confined between 35 to $50 \mathrm{kN} / \mathrm{m}^{2}$. For this load range at this case, bsfc was lower than similar bsfcs' for other former two cases. Engine operation with advanced IT with limited rate of EGR exposes the engine to operate near knock limit that defined its work at high loads. High rates of EGR, as $50 \%$ case, extends loads ranges without engine knock. The reason of the bsfc reduced with $35^{\circ} \mathrm{BTDC}$, and 50\% EGR is the operation with a lean mixture and advanced timing. This case increases the delay period causing high pressure and temperature that compensate the reduction in fuel and absorbed heat by the EGR.

The engine behavior at the retarded IT $\left(12^{\circ} \mathrm{BTDC}\right)$ changes entirely. The engine operation loads range reduced to reach the maximum at $43 \mathrm{kN} / \mathrm{m}^{2}$ and EGR rate $20 \%$, and $34 \mathrm{kN} / \mathrm{m}^{2}$ at $50 \%$ EGR percentage. The reason for this limited load range can be referred to two primary reasons: The operation with a retarded IT makes part of the combustion completed after the piston fall at power stroke. Also, cooled EGR takes part from the combustion liberated energy. The engine combustion chamber design must be changed to extend the load range by increasing the air/fuel mixture turbulence to ensure proper mixing. In addition to increasing injection pressure as references [7, $11 \& 14]$ suggested. 


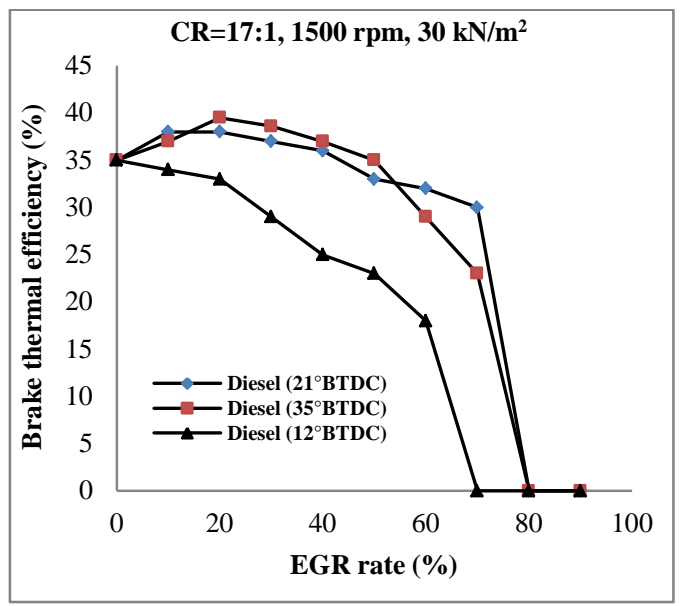

Fig.4 The effect of EGR rate on brake thermal efficiency

Fig. 4 illustrates the impact of cooled EGR on brake thermal efficiency. The brake thermal efficiency increased from $35^{\circ} \mathrm{BTDC}$ a little from the one resulted from the standard IT diesel engine, due to the engine operation with very lean mixture. In the case of engine operating with $12^{\circ}$ BTDC the brake thermal efficiency reduced by about $20.88 \%$ compared to the engine operating in standard IT for the same former mentioned reasons.

Fig. 5 manifests the load effect on the brake thermal efficiency for the studied cases. The maximum brake thermal efficiency was at $35^{\circ} \mathrm{BTDC}$ and $50 \%$ EGR. Followed with $35^{\circ} \mathrm{BTDC}$ and $20 \%$ EGR for the engine operation load range, followed by the engine operation at standard IT. However, for the $12^{\circ} \mathrm{BTDC}$ cases the brake thermal efficiencies were low, but it exceeded that resulted from engine operation at standard IT for limited loads. The last figures clarify that the engine operation with advanced IT and high EGR rate results in higher brake thermal efficiency.

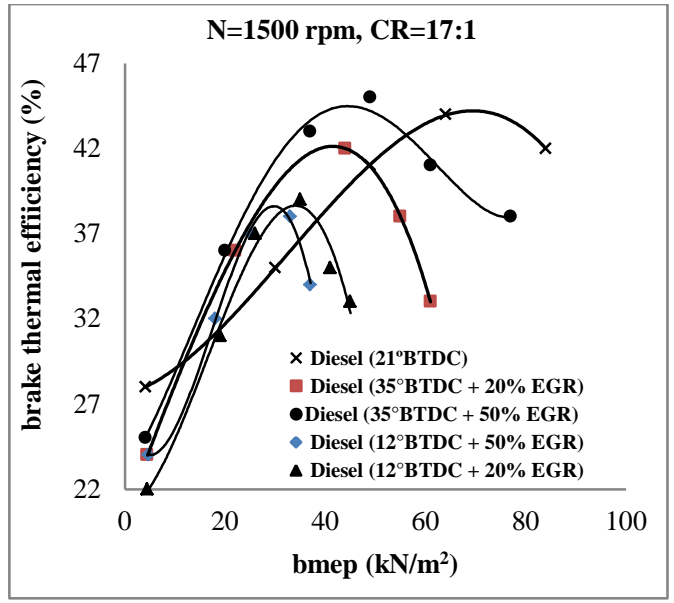

Fig.5 Engine load variation effect on brake thermal efficiency for studied cases

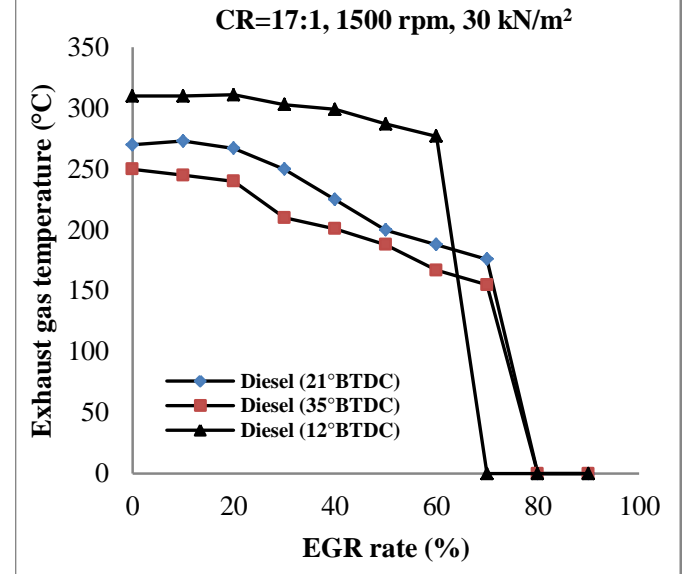

Fig.6 The effect of EGR rate on exhaust gas temperature

Fig. 0 declares the EGK effect on the engine emitted exhaust gas temperatures. Operating the engine in $35^{\circ} \mathrm{BTDC}$ IT resulted in the lower exhaust gas temperatures. The reduction is due to two main factors. The first: cooled EGR that took part from combustion energy. The second: advanced IT resulted in complete combustion before the piston dropped down. If the working with a lean mixture added to these factors the result exhaust gasses with low temperatures. However, for $12^{\circ} \mathrm{BTDC}$ cases the exhaust gas temperatures were higher than similar ones in other instances. IT retardation makes part of the fuel burned in the expansion stroke that another part of fuel may continue burning at exhaust stroke causing these high emitted exhaust gas temperatures. This factor overcame on the effect of EGR addition.

These results can be confirmed by observing Fig. 7 that represents the relation between load variation and emitted exhaust gasses temperatures.

Fig. 8 illustrates the impact of variable rates of EGR on the engine emitted $\mathrm{CO}$ concentrations. $\mathrm{CO}$ concentrations increased with increasing EGR rates for all the IT studied cases. $12^{\circ} \mathrm{BTDC}$ IT resulted in the highest $\mathrm{CO}$ concentrations during $21^{\circ} \mathrm{BTDC}$ the lowest concentrations for the EGR rates from 0 to $35 \%$ range. After this percentage, the $\mathrm{CO}$ concentrations reduced for $35^{\circ} \mathrm{BTDC}$ to become the minimum. The reason for $\mathrm{CO}$ concentration increase for $12^{\circ} \mathrm{BTDC}$ case is the lack of time needed to prepare the air/fuel mixture.

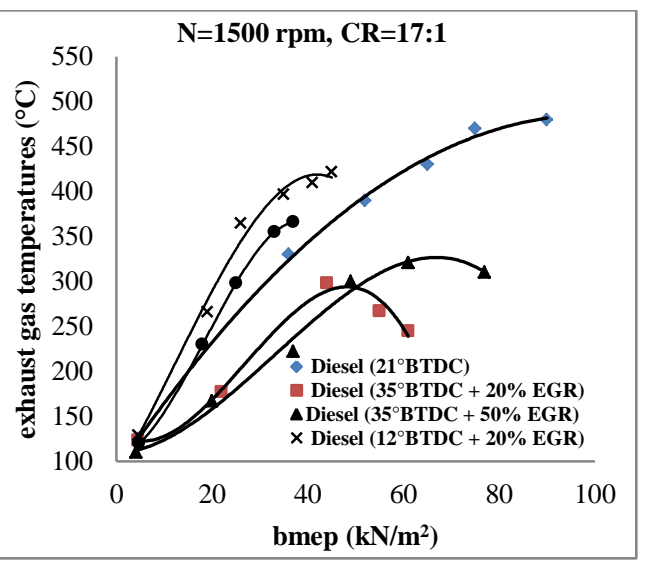

Fig.7 Engine load variation effect on exhaust gas temperature for studied cases 


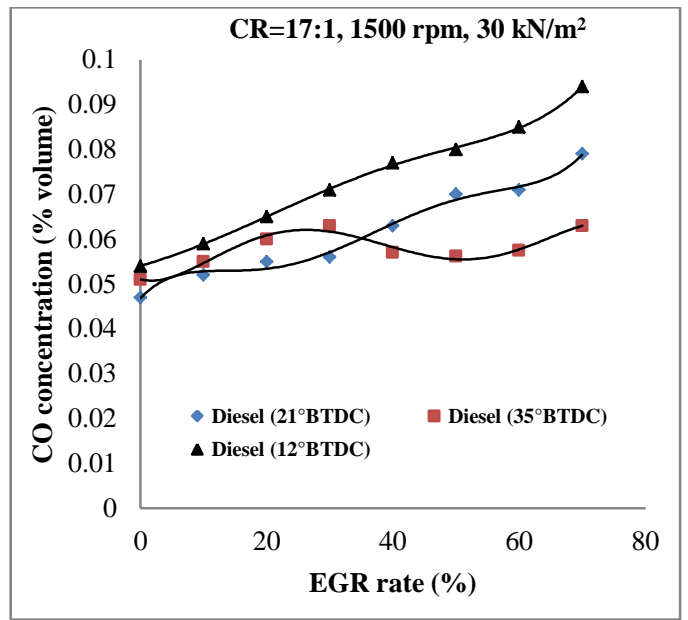

Fig.8 The effect of EGR rate on CO concentrations

The fuel injected before top dead center at very tiny time does not suffice for fuel evaporation and mixing with the air. These concentration reductions for high EGR rate and $35^{\circ}$ BTDC IT was due to the availability of time required for air-fuel mixing. For standard IT case, $\mathrm{CO}$ concentration was at the minimum due to $21^{\circ} \mathrm{BTDC}$ IT gives enough time to the air fuel preparation. In addition to the engine design that resulted in the best performance and the lowest emissions at this IT. Increasing added EGR separates the operational conditions from engine standard conditions that lead to the minimum emissions, so high $\mathrm{CO}$ concentrations appeared..

This effect appeared apparently in Fig. 9 for the studied cases where the two instances of $35^{\circ} \mathrm{BTDC}$ resulted in the minimum $\mathrm{CO}$ concentrations.

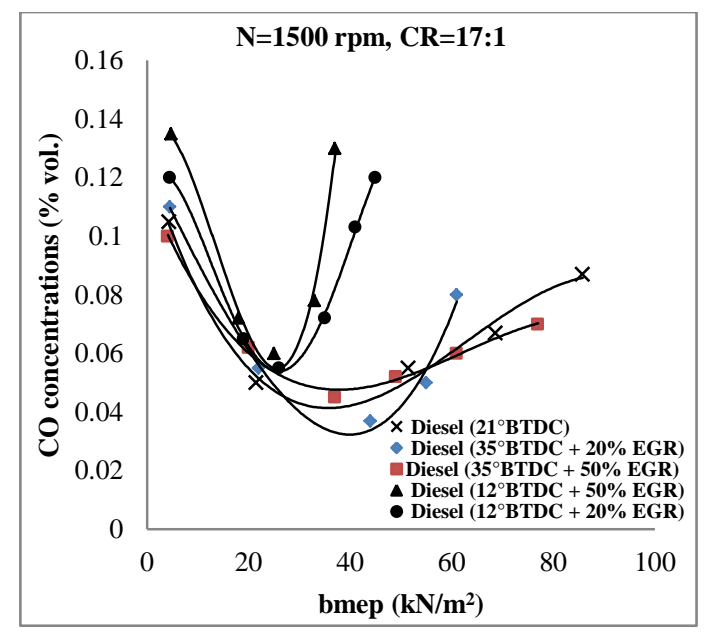

Fig.9 Engine load variation effect on CO concentrations for studied cases

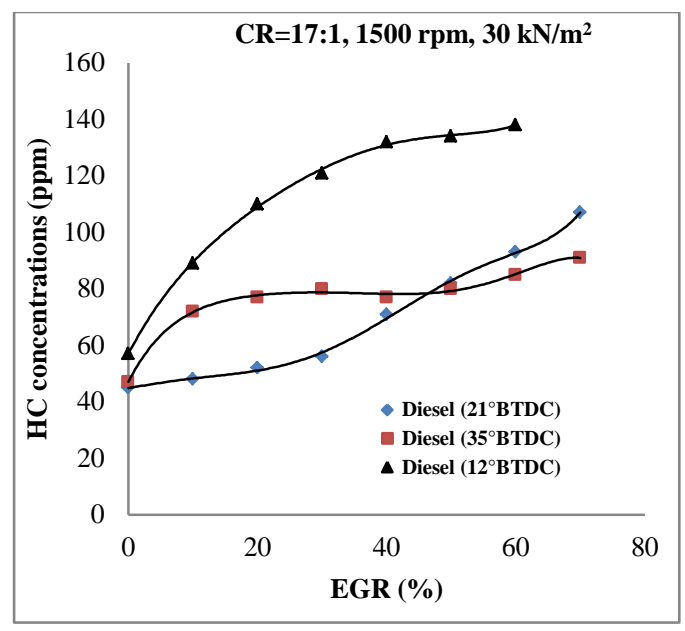

Fig.10 The effect of EGR rate on HC concentrations

Fig. 10 declares the effect of variable EGR rates on HC concentrations. These concentrations took the same $\mathrm{CO}$ concentrations trends with higher concentrations for $12^{\circ}$ BTDC case. The bad mixing with a little mixing time caused a part of the liquid spray to cool at cylinder walls. The other part burned partially in the expansion stroke where neither pressure nor temperature (that is available at compression stroke) required improving the air-fuel mixing.

Adding cooled EGR considered as a primary cause of increasing $\mathrm{HC}$ concentrations. EGR reduces temperature inside combustion chamber and increase the delay period and worked as retarding IT. This effect is evident in Fig. 11 for the studied cases and a wide range of loads. Increasing engine load demands more injected fuel with the individual tested operating conditions resulted in increasing $\mathrm{HC}$ concentrations with high rates.

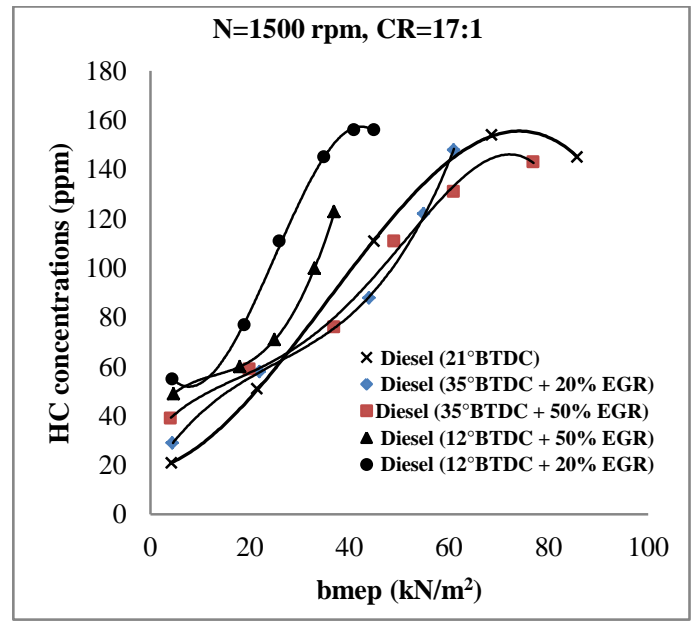

Fig.11 Engine load variation effect on $\mathrm{HC}$ concentrations for studied cases

The noise emitted by the engine divided by noise produced by the combustion process and noise results from the moving 
parts vibration. As EGR interface the combustion process where it dilutes the air-fuel charge and delay combustion. Also, EGR reduces the pressure inside the combustion chamber and absorbs part of the burning heat. As a result, it reduces burning rate and makes the engine less noisy.

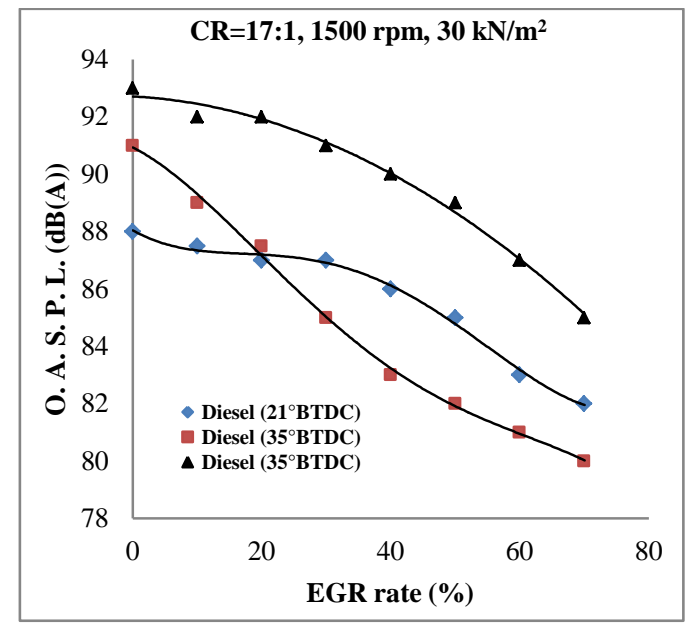

Fig.12 The effect of EGR rate on overall sound pressure rates

As fig. 12 declares, Increasing EGR rates reduced the combustion noise apparently. Engine operating with $12^{\circ}$ BTDC emitted the louder sounds, as a result of a part of the burning occurred in the expansion stroke and may be in exhaust stroke.

Fig. 13 represents the effect of wide load range on the engine emitted noise for the studied cases. The figure indicates that the lower measured noise was with engine operation in $35^{\circ} \mathrm{BTDC}$ and $50 \%$ EGR. Also, increasing load resulted in a limited increment in noise. The variation degree was small because the source (noise source) is monopole. In other hand, increasing the burning fuel quantity caused an increase in the pressure inside the combustion chamber and increased the exhaust gasses pressure during exhaust stroke. All these parameters result in higher measured noise.

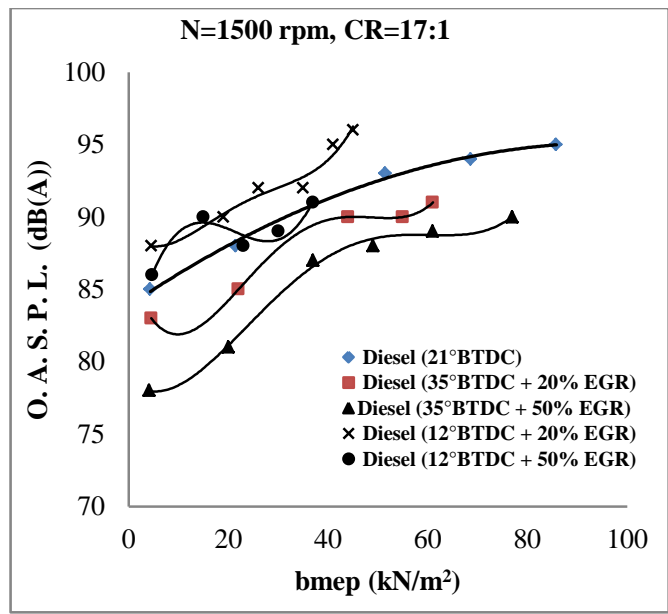

Fig.13 Engine load variation effect on overall sound pressure rates for studied cases

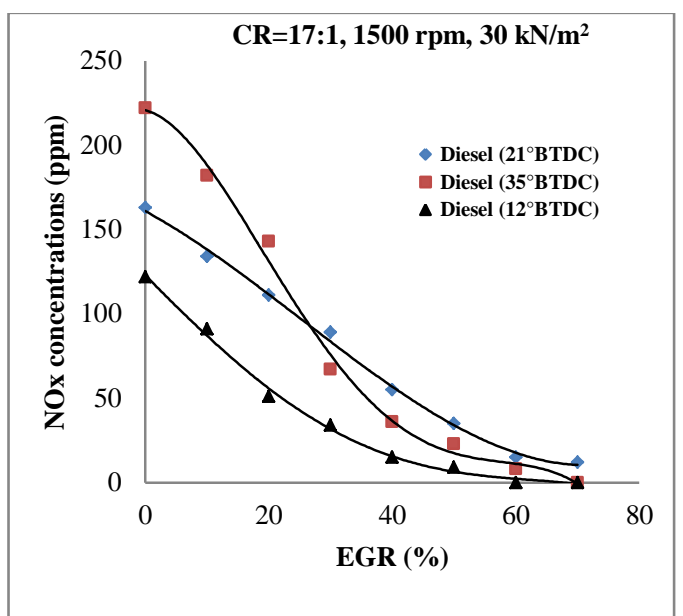

Fig.14, The effect of EGR rate on NOx concentrations

The primary aim, of using EGR, is to reduce NOx concentration in engine exhaust. Also, retarding IT always considered as one of the best methods for NOx reduction. Fig. 14 depicts the meeting of these two factors. Engine operation with retarded IT $12^{\circ}$ BTDC and high EGR rates resulted in very low NOx concentration nearly approached zero at high EGR rate as $60 \%$. Also, the figure indicates that the right mixture preparation with advancing IT caused low NOx concentrations compared with standard IT case at EGR rate higher than $30 \%$. Good mixture preparation means giving cooled EGR greater opportunity to affect the combustion process.

Fig. 15 confirms this trend in spite of load effect on these concentrations. Increasing load increased NOx concentrations highly for neat diesel case while the increment was limited to EGR addition cases.

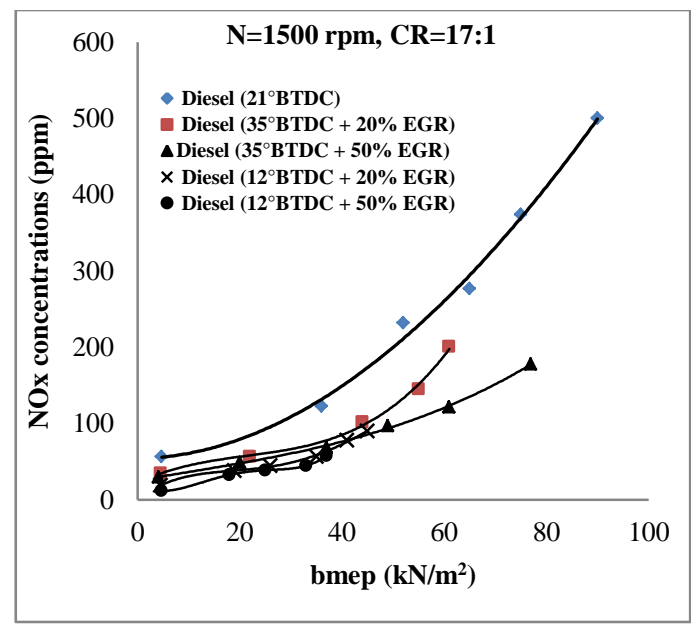

Fig.15 Engine load variation effect on NOx 


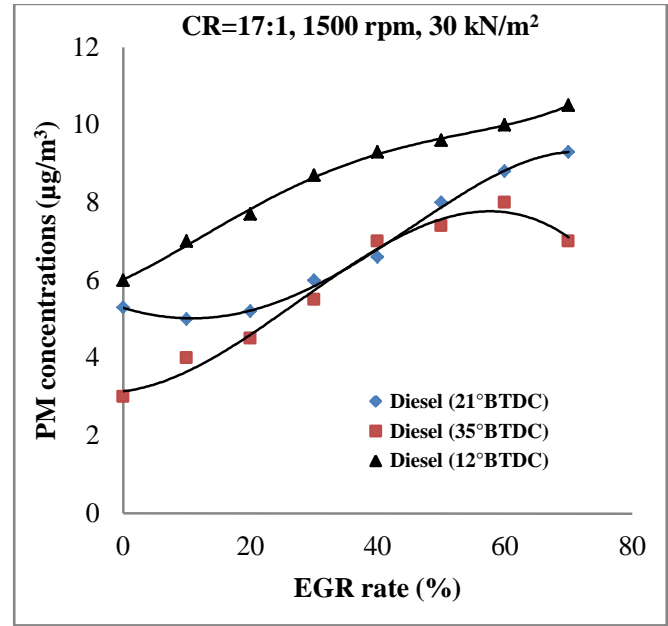

Fig.16 The effect of EGR rate on PM concentrations

EGR causes high PM concentrations. Also, IT retardation causes PM increase. Fig. 16 reveals this trend with $12^{\circ} \mathrm{BTDC}$ IT. However, engine operation without knock at high EGR rates resulted in a reduction of PM concentrations. In view of the fact that, good mixing property and complete burning surmounted the other factors that increased $\mathrm{PM}$ as in $35^{\circ}$ BTDC IT.

Fig. 17 appears these results according to engine load variation. Engine operation with $35^{\circ}$ BTDC and 50\% EGR resulted in the minimum PM concentrations with very low NOx concentration too. The engine functioning in these conditions is suitable for HCCI operation.

Fig. 18 reveals the trade-off relation between PM and NOx concentrations. This relation is important when either pollutant emission specified. NOx typical limitation methods results in increasing PM concentration. In contrast, PM limitation methods results in emitted NOx concentrations increments. The formation conditions and the concentrations development for both PM and NOx varies and conflicts with each others. From the figure, at $35^{\circ}$ BTDC and $50 \%$ EGR resulted in best consequences by reducing both pollutants.

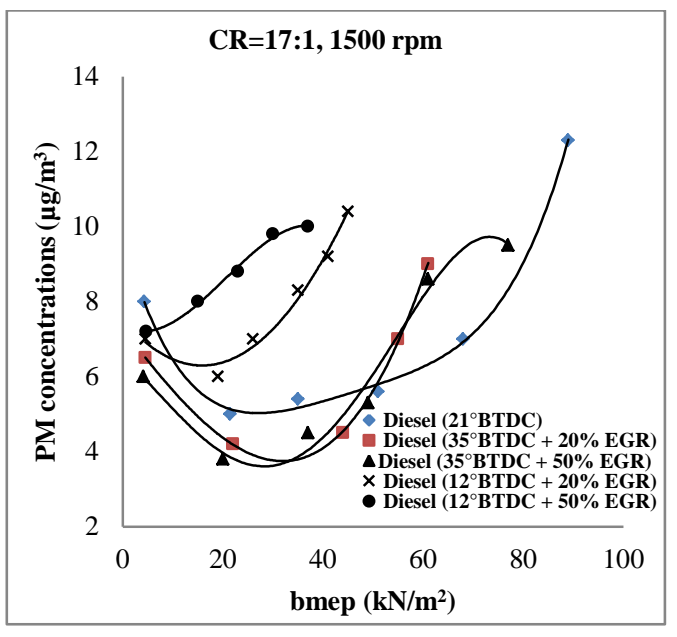

Fig.17 Engine load variation effect on NOx concentrations

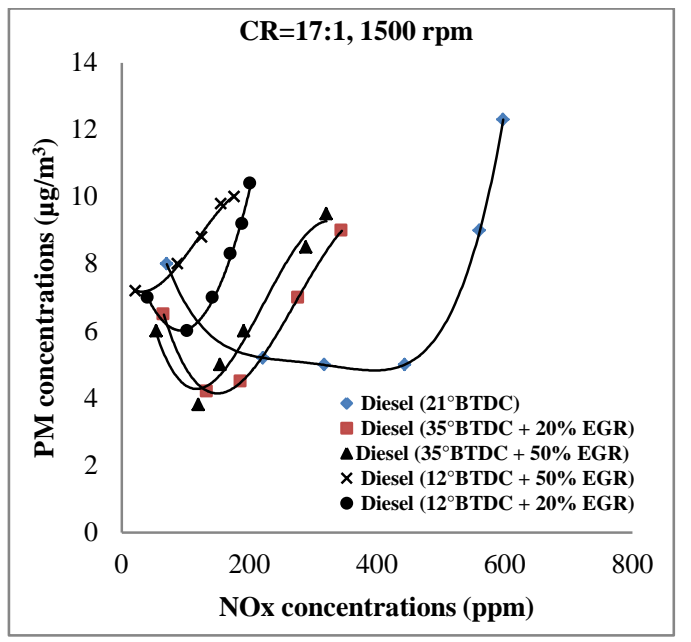

Fig.18 The trade-off relation between PM and NOx concentrations

Although advancing IT increased the produced burning heat but cooled EGR presence with high rates absorbs a part of this generated heat in a way that prevents the formation of NOx and limited it. Also, the good premixed preparation due to IT advance reduces PM formation. The figure represents that using advanced IT with high EGR rate caused a noticeable reduction in the emitted PM and NOx concentrations together. It must be noticed that PM sensitivity for IT variation lower than NOx.

\section{CONCLUSIONS}

A practical study performed on the effect of EGR on the performance and emitted emissions from the exhaust of FIAT DI multi cylinders engine. This study investigates the possibility of operating the engine in HCCI mode by concentrating on IT in addition to EGR rates variation. Two selected injection timings $35^{\circ} \mathrm{BTDC}$ and $12{ }^{\circ} \mathrm{BTDC}$ used; and two EGR rates 20 and $50 \%$ used for each IT. The fundamental results extracted from engine operation at 17:1 compression ratio and $1500 \mathrm{rpm}$ engine speed are:

1- Brake specific fuel consumption increased with IT retardation, and it increased with increasing EGR rate.

2- The EGR rate defines the engine operating load range, depending on the used IT. Also, the extremism, in advancing IT, makes knock appear.

3- Increasing EGR rate increased emitted $\mathrm{CO}$ and $\mathrm{HC}$ concentrations, as well as, retarding IT increased these emissions.

4- The combustion of diesel engine operating in HCCI mode can be controlled by total control of IT with high rates of EGR.

5- High rates of cooled EGR enable the controlling of combustion temperature and start. So, lower burning temperatures mean lower NOx concentrations.

6- Engine operation with advanced IT $35^{\circ}$ BTD with $50 \%$ EGR resulted in good performance characteristics compared with diesel engine operated with standard IT, where: 
- Lower brake specific fuel consumption is obtained.

- Higher brake thermal efficiency is achieved.

- Lower emitted exhaust gas temperatures are obtained.

- Lower $\mathrm{CO}$ and $\mathrm{HC}$ concentrations are obtained.

- Lower NOx concentrations are achieved.

- PM concentrations are low and less than that emitted by standard diesel engine.

- The engine noise level is little.

\section{REFERENCES}

[1] C. Hitache, Experimental investigation of diesel HCCI using a Ricardo E6 single cylinder research engine, MSc thesis, Cranfield University UK, 2006.

[2] E. Supeni, T. F. Yusaf, A. P. Wandel, D. R. Buttsworth and M. Noor, Experimental and modelling investigation of the performance characteristics on diesel HCCI with hydrogen additive- a review, National Conference in Mechanical Engineering Research and Postgraduate Studies (2nd NCMER 2010), Kuantan, Pahang, Malaysia; pp: 580-596, 2010.

[3] C. L. Xing, C. Wei, H. Zhen, A fundamental study on the control of the HCCI combustion and emissions by fuel design concept combined with controllable EGR, Part 1, the basic characteristics of HCCI combustion, Fuel, vol. 84, pp: 1074$1083,2005$.

[4] D. Ganesh and G. Nagarajan, Homogeneous charge compression ignition (HCCI) combustion of diesel fuel with external mixture formation, Energy, vol. 35, pp: 148-157, 2010.

[5] A. Dulbecco, Modelling of diesel HCCI combustion and its impact on pollution emissions applied to global engine system simulation, $\mathrm{PhD}$ thesis, university of Toulouse, 2010.

[6] M. M. Ghazikhani, M. R. Kalateh, Y. K. Toroghi and M Dehnavi, An experimental study on the effect of premixed and equivalence ratios on $\mathrm{CO}$ and $\mathrm{HC}$ emissions of dual fuel $\mathrm{HCCl}$ engine. World Academy of Science, Engineering and Technology, vol. 52, pp: 129-135, 2009.

[7] A. Helmantel and I. Denbratt, HCCI operation of a passenger car DI diesel engine with adjustable valve, SAE paper No. 2006-01 0029, 2006

[8] J. B. Martz, Simulation and model development for auto-ignition and reaction front propagation in low -temperature highpressure lean burn engines, $\mathrm{PhD}$ thesis, University of Michigan, 2010.

[9] J. O. Olsson, P. Tunestal, J. Ulfvik and B. Johansson, The effect of cooled EGR on emissions and performance of a turbocharged HCCI engine, SAE Paper 2003-01-0743, 2003.

[10] W. A. Abdelghaffar, NOx formation inside HCCI engines, American Journal of Science and Industrial research, vol. 1, No 2, pp: 293-302, 2010

[11] M. T. Chaichan and A. M. Saleh, Practical investigation of the effect of EGR on DI multi cylinders diesel engine emissions, $\mathrm{Al}$ Anbar University J, (In press), 2012.

[12] P. Risberg, D. Johansson, J. Andrae, B. P. Kalghatgi, and H. E Angstrom, The influence of $\mathrm{NO}$ on the combustion phasing in an HCCI engine, SAE paper No. 2006-01-0416, 2006.

[13] G. Chen, I. Norimasa and Z. Huang, Numerical study of EGR effects on reducing the pressure rise rate of HCCI engine combustion, Front. Energy Power Eng., China, vol. 4, No. 3, pp: 376-385, 2010.

[14] H. Machrafi, S. Cavadias and P. Guibert, An experimental and numerical investigation on the influence of external gas recirculation on the HCCI auto-ignition process in an engine: Thermal, diluting, and chemical effects, Combustion and Flame, vol. 155 , No. 3, pp: 476-489, 2008.

[15] W. L. Hardy and R. D. Reitz, A Study of the effects of high EGR, high equivalence ratio, and mixing time on emissions levels in a heavy duty diesel engine for PCCI combustion, SAE Paper No. 2006-01-0026, 2006.
[16] M. T. Chaichan, K. I. Abaas and A. H. Naser, Study of the effect of exhaust gas recirculation on performance and emitted noise of an engine fuelled with diesel fuel, Association of Arab Universities Journal of Engineering Science, vol. 20, No. 1, pp: 43-59, 2013.

[17] L. Franklin, Effects of HCCI control strategies on particulates emissions of ethanol fuel, $\mathrm{PhD}$ thesis, University of Minnesota, USA, 2010.

[18] A. Tsolakis, A. Megaritis and D. Yap, Application of exhaust gas fuel reforming in diesel and homogeneous charge compression ignition (HCCI) engines fuelled with bio-fuels, Energy, vol. 33, No. 3, pp: 462-470, 2008.

[19] E. L. Keeting, Applied combustion, $2^{\text {nd }}$ edition, Taylor \& Francis Group, LLC, 2007.

[20] ASHREA GIUDE LINE. Guide engineering analysis of experimental data, Guideline 2-1986.

TABLE 1

THE USED ENGINE SPECIFICATIONS

\begin{tabular}{|l|l|}
\hline Engine type & 4cyl., 4-stroke \\
\hline Engine model & TD 313 Diesel engine rig \\
\hline Combustion type & DI, water cooled, natural aspirated \\
\hline Displacement & $3.666 \mathrm{~L}$ \\
\hline Valve per cylinder & two \\
\hline Bore & $100 \mathrm{~mm}$ \\
\hline Stroke & $110 \mathrm{~mm}$ \\
\hline Compression ratio & 17 \\
\hline Fuel injection pump & $\begin{array}{l}\text { Unit pump } \\
26 \mathrm{~mm} \text { diameter plunger }\end{array}$ \\
\hline Fuel injection nozzle & $\begin{array}{l}\text { Hole nozzle, } 10 \text { nozzle holes } \\
\text { Nozzle hole dia. }(0.48 \mathrm{~mm}) \\
\text { Spray angle }=160^{\circ} \\
\text { Nozzle opening pressure }=40 \mathrm{Mpa}\end{array}$ \\
\hline
\end{tabular}

TABLE 2

THE USED DIESEL FUEL SPECIFICATIONS

\begin{tabular}{|l|c|}
\hline Source & Iraq \\
\hline Cetane No. & 48.5 \\
\hline Boiling point & $280^{\circ} \mathrm{C}$ \\
\hline Density & $820-833 \mathrm{~kg} / \mathrm{m}^{3}$ \\
\hline Stoichiometric A/F & 14.5 \\
\hline Sulphur content & $\% 1$ \\
\hline LHV & $42600 \mathrm{~kJ} / \mathrm{kg}$ \\
\hline
\end{tabular}

TABLE 3

MEASURMENT TYPE AND ACCURECY OF THE RECENT STUDY EQUIPMENT

\begin{tabular}{|l|c|}
\hline \multicolumn{1}{|c|}{ Measurements } & Accuracy \\
\hline Temperature & $\pm 0.36 \%$ \\
\hline Fuel flow rate & $\pm 0.96 \%$ \\
\hline Air flow rate & $\pm 0.82 \%$ \\
\hline EGR flow rate & $\pm \% 0.88$ \\
\hline Engine speed & $\pm 0.74 \%$ \\
\hline Engine torque & $\pm 1.4 \%$ \\
\hline Sound pressure level & $\pm 0.67 \%$ \\
\hline Emitted emissions concentrations & $\pm 0.22 \%$ \\
\hline PM concentrations & $\pm 0.68 \%$ \\
\hline Injection timing variation & $\pm 0.8 \%$ \\
\hline
\end{tabular}


International Journal of Engineering Trends and Technology (IJETT) - Volume 19 Number 3 - Jan 2015 NOTATION

\begin{tabular}{|l|l|}
\hline bmep & Brake mean effective pressure \\
\hline bp & brake power \\
\hline bsfc & Brake specific fuel consumption \\
\hline BTDC & Before top dead center \\
\hline CO & Carbon monoxide \\
\hline $\mathrm{CO}_{2}$ & Carbon dioxide \\
\hline HCCI & Homogeneous compression ignition engine \\
\hline HC & Unburnt hydrocarbons \\
\hline IT & Injection timing \\
\hline LHV & Fuel lower heating value \\
\hline \multicolumn{1}{|c|}{$\dot{m}_{f}$} & Fuel flow rate mass $(\mathrm{kg} / \mathrm{sec})$ \\
\hline \multicolumn{1}{|c|}{$\dot{m}_{a, a c t .}$} & Actual air flow rate mass $(\mathrm{kg} / \mathrm{sec})$ \\
\hline \multicolumn{1}{|c|}{$\dot{m}_{a_{t h e o .}}$} & Theoretical air flow rate mass $(\mathrm{kg} / \mathrm{sec})$ \\
\hline $\mathrm{N}$ & Engine speed \\
\hline $\mathrm{NOx}$ & Nitric oxides \\
\hline $\mathrm{PM}$ & Particulate matters \\
\hline $\mathrm{T}$ & Engine torque \\
\hline \multicolumn{1}{|c|}{$\eta_{b t h .}$} & Brake thermal efficiency \\
\hline
\end{tabular}

